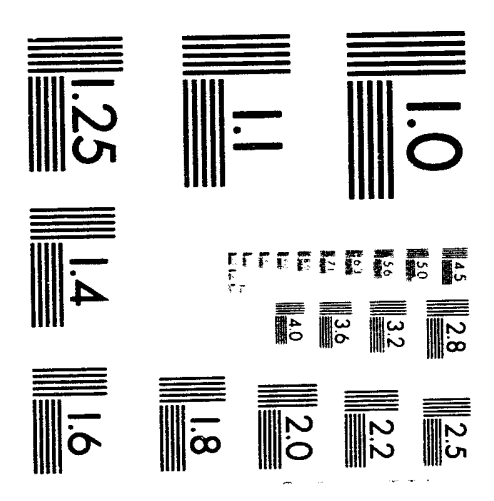



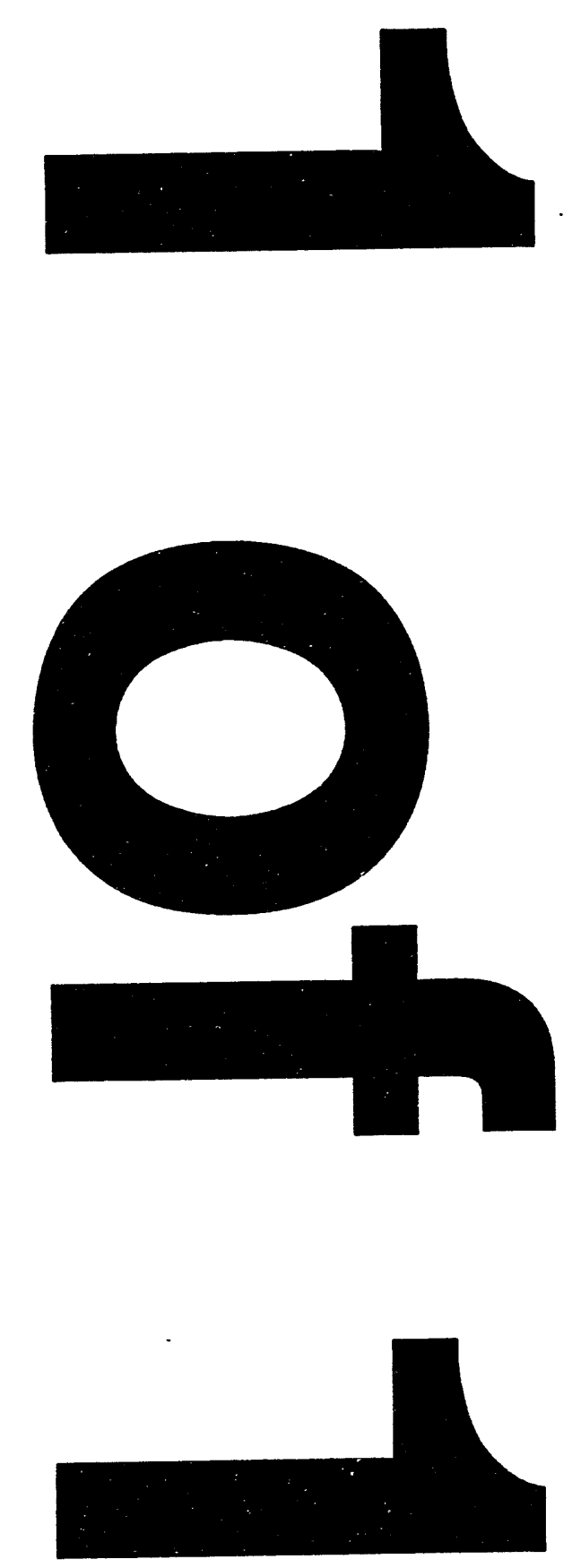
GA-A21542

\section{DIVERTOR PUMPING AND OTHER REACTOR APPLICATION ISSUES FOR H-MODE}

by

R.D. STAMBAUGH, S.L. ALLEN, ${ }^{(a)}$ N.H. BROOKS, D.N. HILL, ${ }^{(a)}$

D.L. HILLIS, ${ }^{(b)}$ A.W. HYATT, G.L. JACKSON, S. KONOSHIMA, (c)

E.A. LAZARUS,(b) A.W. LEONARD, S.I. LIPPMANN, M.A. MAHDAVI,

R. MAINGI,(b) M.M. MENON,(b) T.H. OSBORNE, T.W. PETRIE, G.D. PORTER, $(a)$ M.E. RENSINK, ${ }^{(a)}$ M.J. SCHAFFER, D.P. SCHISSEL, G.M. STAEBLER, M.E. WADE, ${ }^{(b)}$ and R.D. WOOD ${ }^{(a)}$

This is a preprint of a paper to be presented at the Fourth H-Mode Workshop, November 15-17, 1993, Naka, Japan, and to be printed in Plasma Physics and Controlled Fusion.

Work supported by

U.S. Department of Energy

Contract Nos. DE-AC03-89ER51114, W-7405-ENG-48, DE-AC05-840R21400, DE-AC03-76DP00789, and DE-FG03-89ER51121.

(a) Lawrence Livermore National Laboratory.
(b) Oak Ridge National Laboratory.
(c) Japan Atomic Energy Research Institute.

GENERAL ATOMICS PROJECT 3466 JANUARY 1994
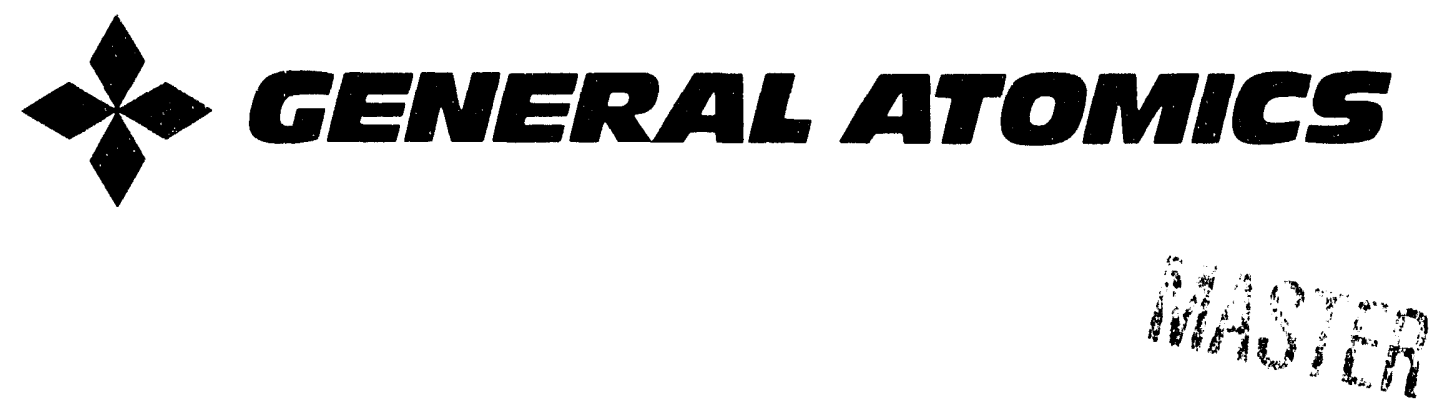


\title{
Divertor pumping and other reactor application issues for $\mathrm{H}$-mode*
}

\author{
R.D. Stambaugh, S.L. Allen, ${ }^{a}$ ) N.H. Brooks, D.N. Hill, ${ }^{a)}$ D.L. Hillis, \\ A.W. HyatT, G.L. Jackson, S. Konoshima, ${ }^{c}$ E.A. Lazarus, ${ }^{b}$ ) A.W.

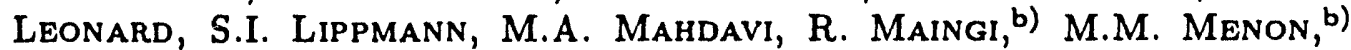 \\ T.h. Osborne, T.W. Petrie, G.D. Porter,a) M.E. Rensink, a) M.J. \\ Schaffer, D.P. SChissel, G.M. Staebler, M.R. Wade, ${ }^{\text {b) and }}$ \\ R.D. WOODa)
}

General Atomics, P.O. Box 85608, San Diego, California 92186-9784, U.S.A.

\section{(Received}

\begin{abstract}
We summarize results from DIII-D in regard to issues for reactor application of $\mathrm{H}$-mode. Recently, DIII-D has begun to operate a cryopump $\left(\mathrm{D}_{2}\right.$ pumping speed $=31,000 \ell / \mathrm{s}$ at a pressure of $2 \mathrm{mTorr}$ ). Initial results are very favorable for density control in $\mathrm{H}$-mode. The plasma density could be reduced by $50 \%$. Energy confinement is unchanged so the temperature rises in proportion to the density drop. Ability to access these less collisional plasmas in $\mathrm{H}$-mode is favorable to current drive application. With the all-graphite wall, impurity accumulation has been eliminated. The exceedingly good confinement of VH-mode offers the possibility of retaining good confinement while radiating copious power from the plasma edge using injected noble gas impurities.
\end{abstract}

\section{Introduction}

The energy confinement improvement in the tokamak afforded by $\mathrm{H}-$ and $\mathrm{VH}$-mode is of obvious great benefit in improving the performance of future experiments and reactors. Other tendencies of $\mathrm{H}$ - and $\mathrm{VH}$-mode have raised concern about the reactor applicability of these modes. The observations that in $\mathrm{H}$-mode the transport reduction is strongest near the plasma edge (the "transport barrier") and that the density increases uncontrollably while $\mathrm{D}_{\alpha}$ recycling light drops have raised the concern that $\tau_{\mathrm{p}}$ may be too large in relation to $\tau_{\mathrm{E}}$ (a reactor needs $\tau_{\mathrm{He}}^{*} / \tau_{\mathrm{E}}<15$ ). ELM-free $\mathrm{H}$ phases are often terminated after continuous impurity buildup in the core.

Results from DIII-D are rather favorable on all these issues. Since we added a divertor cryopump in early 1993, we have obtained good pump-out rates of fuel and helium in H-mode (Mahdavi et al., 1993a; Mahdavi et al., 1993b; Hillis et al., 1993). By removing the source of nickel (we covered all Inconel surfaces in DIII-D with graphite), we eliminated the buildup of high $Z$ impurities in VH-mode (Konoshima et al., 1992; Konoshima et al., 1993; Wood et al., 1993). Low $Z$ impurities have been suppressed with boronization. Good confinement regimes have been found with a thick SOL for good impurity screening (Lippmann et al., 1992). The flat density profiles of $\mathrm{H}$-mode when coupled with the ELMs periodically breaching the transport barrier are favorable to impurity control (Content et al., 1990; Perry et al., 1991). Indeed the excess of confinement afforded by VH-mode may be quite helpful to solving the divertor problem by allowing noble gas impurities to be used as a radiating mantle just inside the separatrix.

* Work supported by the U.S. Department of Energy under Contract No8. DE-AC03-89ER51114, W-7405ENG-48, DE-AC05-84OR21400, DE-AC03-76DP00789, and DE-FG03-89ER51121.

a) Lawrence Livermore National Laboratory.

b) Oak Ridge National Laboratory.

c) Japan Atomic Energy Research Institute. 


\section{Cryopump}

In early 1993, a cryopump was installed under the divertor baffle in DIII-D (Mahdavi et al., 1993a) (Fig. 1). The pump is toroidally symmetric mechanically and electrically in order to minimize electric potentials between the pump and the vessel wall during disruptions. The pump was engineered to withstand both the Joule heating and the $\vec{J} \times \vec{B}$ forces from the toroidal currents in the pump. The pump consists of an inner liquid helium circuit, a $\mathrm{LN}_{2}$ shield, and an outer room temperature shield. The measured pumping speed is $24000 \mathrm{l} / \mathrm{s}+$ $3570 \mathrm{l} / \mathrm{s} \times \mathrm{P}_{\text {baffle }}$ (mTorr). Typical operation of the pump in the experiments reported in this paper was to have the pump warm during the first half of a run day to produce reference discharges (e.g. 79882 and 79744 in Table 1) and then to make the pump cold for the later half of the day to obtain companion pumped discharges (e.g. 79884, 79745). With the pump cold, it can be turned "on or off" by moving the outer divertor strike point toward or away from the pump aperture. Strong pumping is obtained with the strike point within $5 \mathrm{~cm}$ of the divertor ring (unbiased in all these experiments). This continuous adjustability of the pumping rate has been used to make closed loop feedback for the plasma density (Mahdavi et al., 1993b).

\section{Density control in ELMing $\mathbf{H}-$ mode}

Initial work with the pump done in ELMing $\mathrm{H}$-mode has been reported earlier (Mahdavi et al., 1993a; Mahdavi et al., 1993b) and will only be briefly summarized here. In unpumped $\mathrm{H}$-mode discharges, after the L-H transition the density rises rapidly until the onset of ELMs clamps the density (See Fig. 2). The final density is set by the current, $\bar{n}_{\mathrm{e}}\left(10^{18} \mathrm{~m}^{-3}\right)=6 \times \mathrm{I}_{\mathrm{p}}$ (MA). With the pump on (Fig. 2), the density increase during the ELM-free phase still occurs, but when the ELMs begin, the density is pumped out back down to the L-mode level. Pumping rates were large $(40$ Torr $\ell / \mathrm{s})$ compared to beam fueling rates $(10$ Torr $\ell / \mathrm{s})$. With a typical plasma inventory of $\sim 10$ Torr $\ell$, the pumping time constant $N /(\mathrm{dN} / \mathrm{dt})$ was only 0.25 seconds.

\section{Complete carbon-tile coverage}

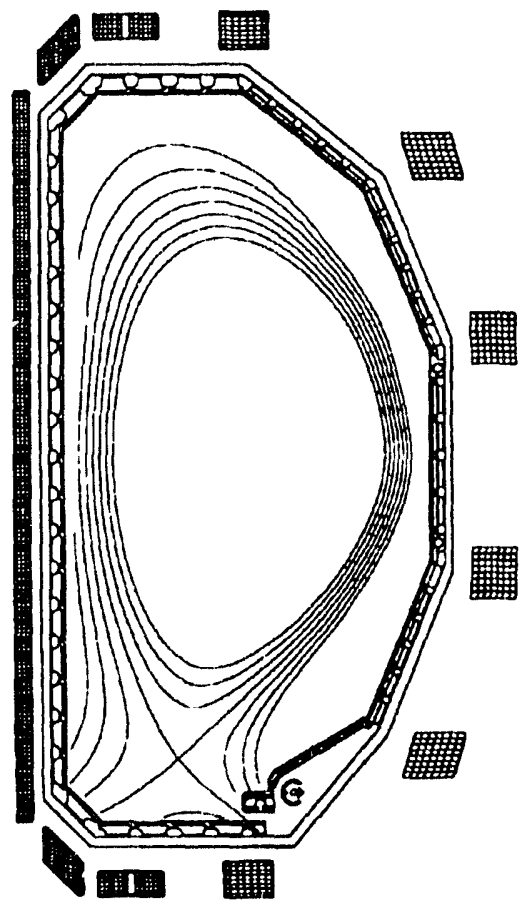

\section{Cryopump under divertor baffle}

- Water-cooled graphite and boron nitride tiles

- Water-cooled bias ring $750 \mathrm{~V}, 20 \mathrm{kA}$ operated two years

- Cryopump 30,000 l/sec, 300w

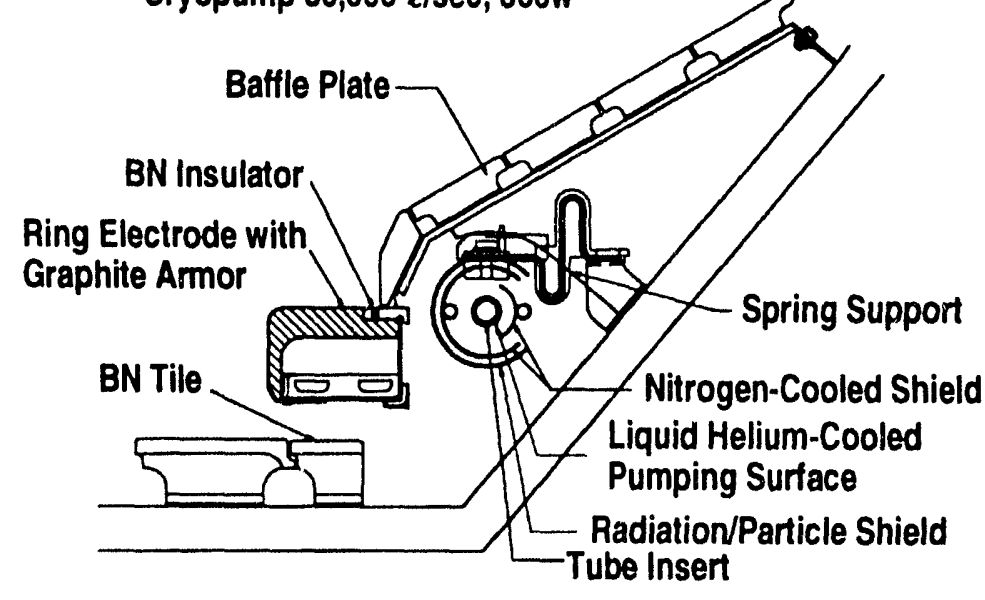

Figure 1. New divertor and first wall hardware installed in DIII-D in January, 1993. 
Table 1

ELM-Free Discharges Studied

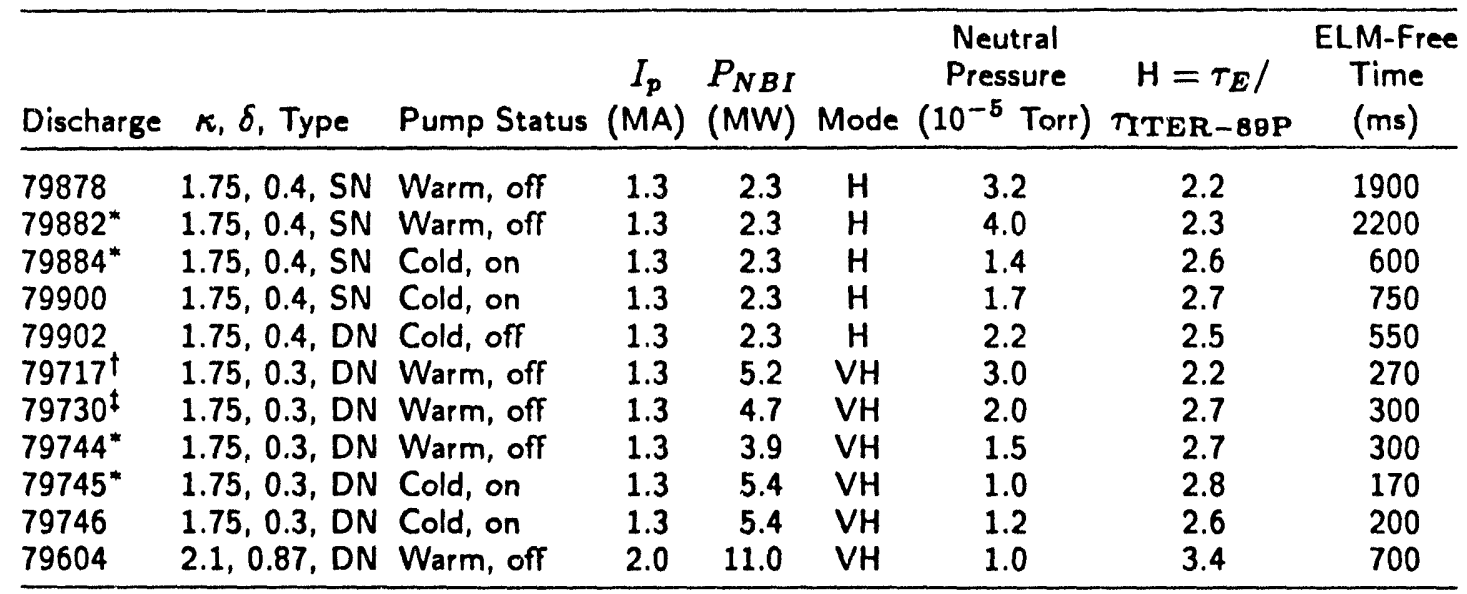

*Discharges compared in detail in this paper.

tVacuum vessel in a gassy condition.

${ }^{t}$ After a weekend bake.

This very effective particle removal has been used to feedback regulate densities a factor of two apart at the same current, something never before possible in DIII-D. The result of these experiments was that $\tau_{\mathrm{E}}$ in $\mathrm{H}$-mode depends on current and not density (Mahdavi et al., 1993b; Schissel etal., 1993). Energy confinement is not affected by pumping. When the density is reduced the temperature rises proportionally (Fig. 2). Because collisionality is reduced and more NBI power goes to the ions, the ion temperature increases more than the electron temperature.

Studies of gas accountability in these discharges were also interesting (Mahdavi et al., 1993a). The plasma inventory and neutral beam inputs ( $10-30$ Torr $\ell)$ are small compared to the 100-200 Torr $\ell$ input by the gas puff system, pumped by the pump, and either pumped or released by the graphite wall. When the graphite wall is full of deuterium, the pump steadily depletes the wall inventory from discharge to discharge. When the wall is well degassed by helium glow wall conditioning, the wall can pump more gas than the cryopump and so the wall inventory builds up from discharge to discharge.

riecently (Hillis et al., 1993), argon frost was applied to the cryopump to enable it to pump helium. Effective helium pumpout $\left(\tau_{\mathrm{HE}}^{*} / \tau_{\mathrm{E}} \sim 14\right)$ was achieved. Evidently adequate particle removal of both fuel and helium can be obtained in ELMing $\mathrm{H}$-mode.

\section{Pump effects in ELM-free $\mathrm{H}$ - and $\mathrm{VH}$-mode}

The highest performance in DIII-D is obtained in highly elongated and triangular equilibria [Fig. 3(c), e.g. discharge 79604]. In the VH phase of these discharges, $H \equiv \tau_{\mathrm{E}} / \tau_{\mathrm{ITER}-80 \mathrm{P}}$ has reached 3.4 and $n_{D}(0) T_{i}(0) \tau_{\mathrm{E}}^{\text {TOTAL }}$ has reached $5 \times 10^{20} \mathrm{keV} \mathrm{s} / \mathrm{m}^{3}$ (Lazarus et al., 1993). Because the $\mathrm{X}$-points are so close to the inner corners of the vacuum vessel, it is very difficult to design any kind of ITER-like slot divertor around this configuration. We also cannot pump these plasmas because the outer strike point is so far away from the pump. Recently a significant campaign (Lazarus et al., 1993) was made to ascertain the highest performance that could be obtained with the lower elongation, lower triangularity equilibrium shown in Fig. 3(b). This equilibrium would allow the installation of a slot divertor. As it happened, this configuration also could be pumped by the existing pump, and the pump was used on various occasions in an unsuccessful attempt to improve the performance. The VH-mode performance of the low $\kappa$, low $\delta$ plasmas could not be made as good as that of the high $\kappa$, high $\delta$ plasma shape in regard to 
confinement quality and length of the ELM-free period (Table 1). It is not the purpose of this paper to report on the connection of confinement quality and plasma shape. Nevertheless, this campaign yielded interesting data on pumping the ELM-free phases of $\mathrm{H}$ - and VH-mode. All discharges were deuterium. Two discharge sequences are reported (Table 1). Discharges 78978-79902 were single-null [Fig. 3(a)] at $\mathrm{B}_{\mathrm{T}}=2.1 \mathrm{~T}$ with neutral beam power just above the $\mathrm{L}-\mathrm{H}$ transition threshold in order to obtain a very long ELM-free period. Discharges 79717-79746 were double-null [Fig. 3(b)] at $\mathrm{B}_{\mathrm{T}}=1.6 \mathrm{~T}$ and part of the campaign to study performance versus shape and so were run at higher power to reach high $\beta_{\mathrm{T}}$.

\subsection{Confinement quality and midplane neutral pressure}

A result of long standing $\mathrm{H}$-mode studies, supported by the data in Table 1, is that efforts to reduce recycling and gas inventories in the vacuum vessel are rewarded with better confinement (Stambaugh et al., 1990). The data of Table 1 show a clear correlation of best $\mathrm{H}$ factor at lowest neutral pressure near the plasma midplane where the SOL is thinnest. A particular sequence is instructive. Discharge 79717 was the best result that could be obtained on a Friday with a gassy condition. A weekend bake reduced the neutral pressure and $\mathrm{H}$ increased somewhat in discharge 79730 (Monday). In discharges 79744-46 (Tuesday), neutral pressures as low as in our best VH-mode (79604) were obtained along with the best $\mathrm{H}$ factor for this shape. Making the pump cold reduced neutral pressure everywhere in the vacuum vessel but substantially shortened the ELM free period, resulting in lower peak performance.

\subsection{Effect of pumping on the core plasma}

During ELM-free H- or VH-mode, the pump had the same strong effect on the core plasma as in ELMing $\mathrm{H}$-mode (Fig. 4). The density was reduced about $20 \%-30 \%$ all across the profile and the temperature rose proportionally with no change in overall $\tau_{E}$.

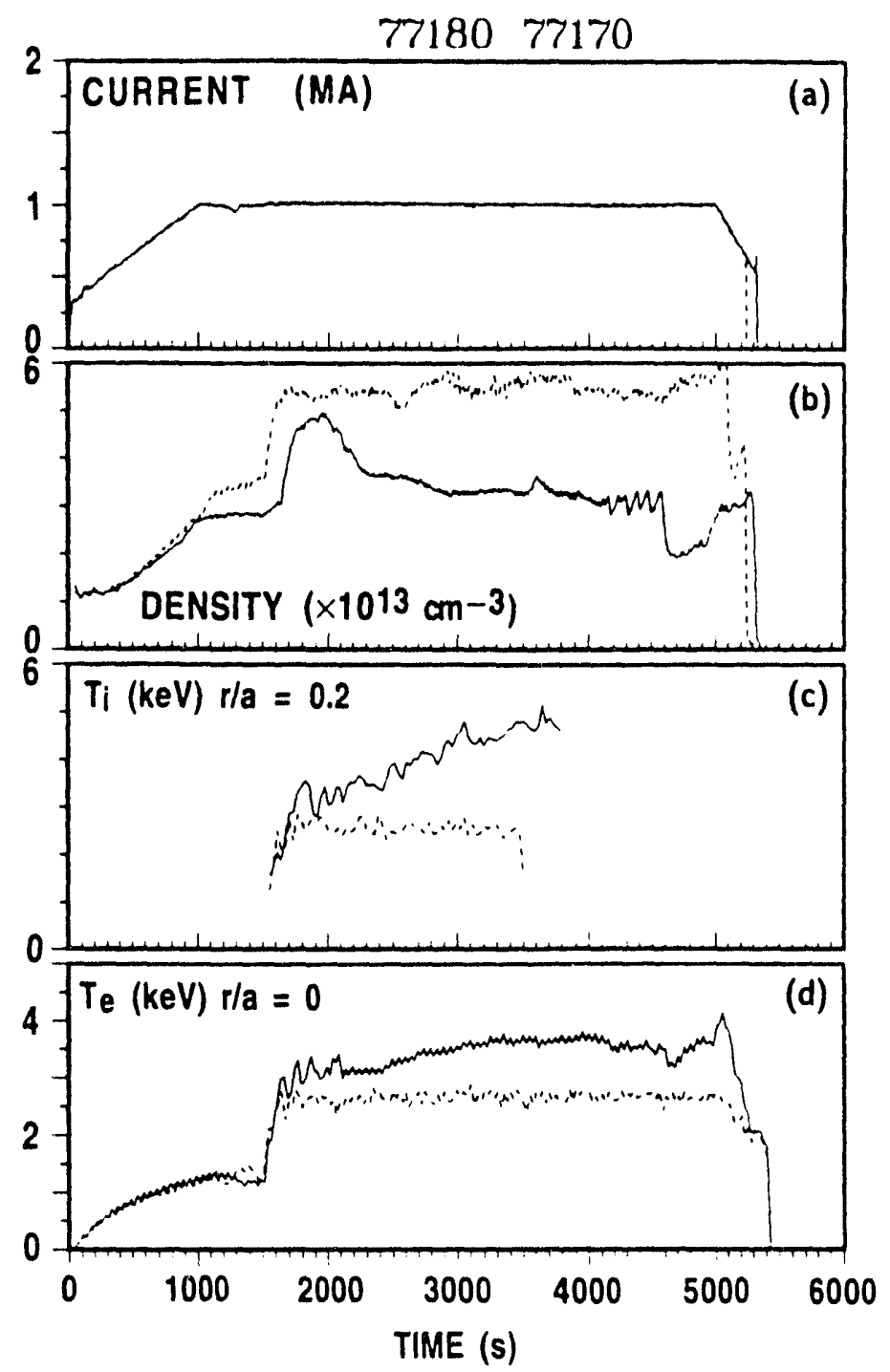

Figure 2. A comparison of two otherwise similar (a) plasma current, (b) line average electron density, (The sudden density drop at $t \simeq 4.6 \mathrm{~s}$ is due to a transition back to the $\mathrm{L}$-mode. The transition is due to reduced auxiliary heating power at $\mathrm{t} \simeq 4.2 \mathrm{~s}$.) (c) ion temperature at normalized radius 0.2 , (d) central electron temperature. On this time scale, ELMs are present throughout the H-phase. $\mathrm{H}$-mode shots, with and without divertor pumping. 

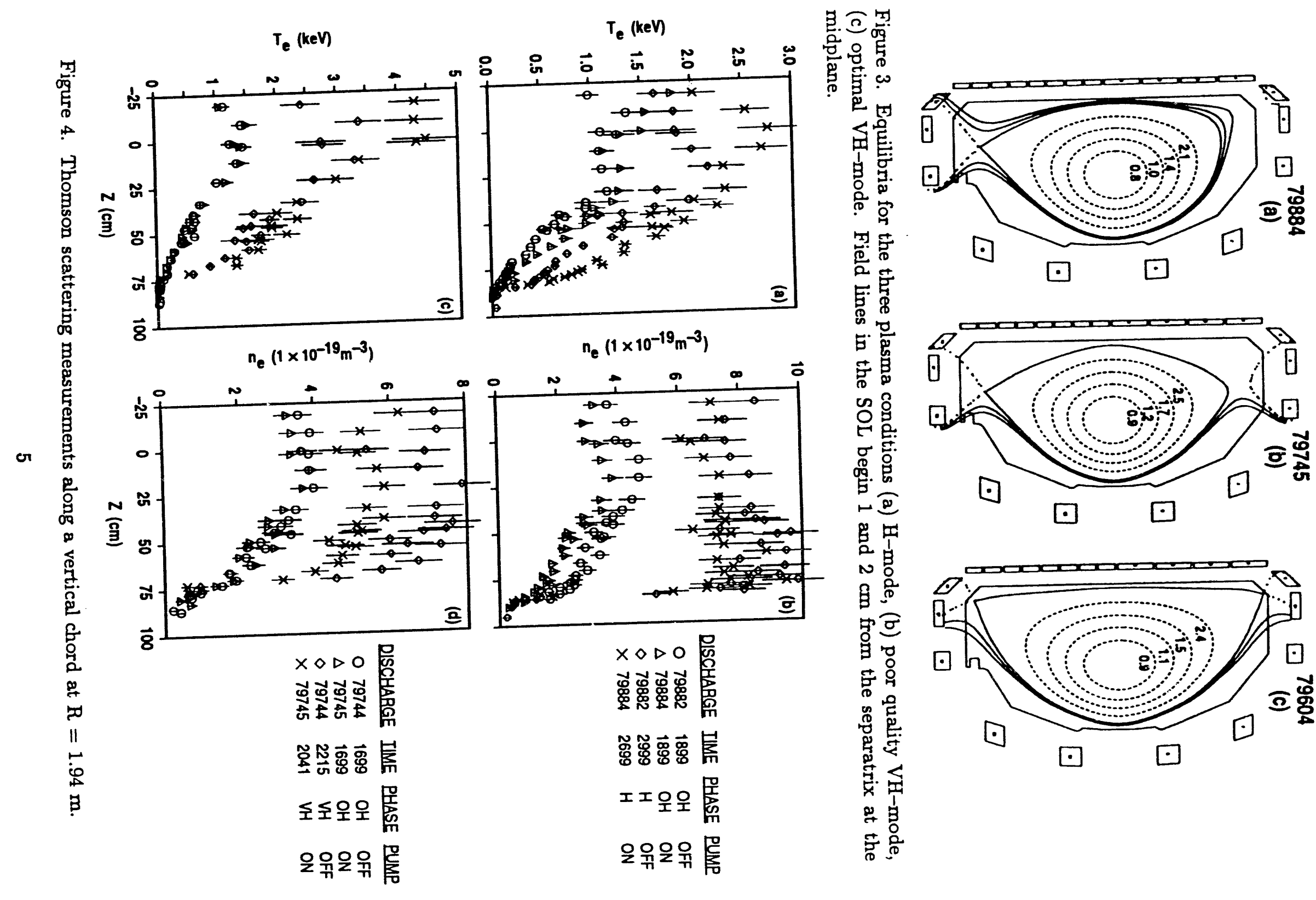

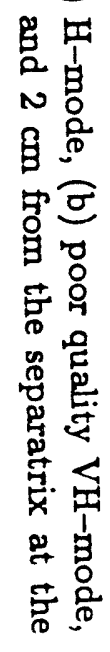

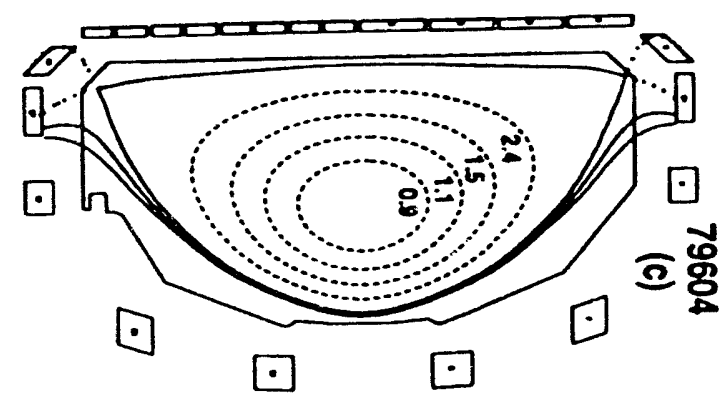




\subsection{Effects on SOL plasma}

In the ELM-free H-mode, the SOL density and temperature $\left(<10^{19} \mathrm{~m}^{-3},<50 \mathrm{eV}\right)$ were considerably lower than in the Ohmic or $\mathrm{L}$-mode phase of the same discharge. Pumping further lowered SOL $n_{e}$ and $T_{e}$ but only slightly.

In the ELM-free low $\kappa$, low $\delta$ VH-mode (79745), the SOL density and temperature $\left(<10^{19} \mathrm{~m}^{-3},<40 \mathrm{eV}\right)$ were again lower than in the Ohmic phase of the same discharge and pumping produced slightly lower values.

In contrast, in the optimal unpumped ELM-free VH-mode (79604), SOL densities and temperatures were considerably higher than in the $\mathrm{H}$ or Ohmic phases (which were about equal). This last observation supports an earlier observation by Lippmann (Lippmann et al., 1992) that VH-mode had a thicker SOL than Ohmic, L-, or $\mathrm{H}$-mode. A thick SOL in a good confinement mode is very useful for impurity screening. Lippmann found that VH-mode plasmas had the lowest impurity levels. Why the low $\kappa$, low $\delta, \mathrm{VH}$-mode plasmas have the opposite SOL behavior is not known.

\subsection{Gas accountability}

Earlier we discussed how the vessel wall can be either a net source or net sink of fuel particles and how degassing the wall improves $\tau_{E}$ performance. On an absolute scale though, all the discharges in Table 1 were in the regime where the wall was strongly pumping. Figures $5(\mathrm{a}, \mathrm{b})$ show various key time traces related to gas flows. Typically, the wall absorbed $\sim 200$ Torr $\ell$ of gas per discharge.

In the ELM-free period of $\mathrm{H}$-mode, effective pumping was obtained. After the $\mathrm{L}-\mathrm{H}$ transition, the rate of rise of the plasma density was cut in half from 57 Torr $\ell / s$ unpumped to 27 Torr $\ell / \mathrm{s}$ pumped. The pressure uni' 2 the baffle dropped from $3 \mathrm{mTorr}$ in the unpumped case (79882) to $0.5 \mathrm{mTorr}$ in the pumped case (79884). The resulting pumping rate of $13 \mathrm{Torr} / \mathrm{s}$ only accounts for about $40 \%$ of the reduction in the rate of rise of density. The discharge with the pump cold had a much lower neutral pressure at the midplane at all times compared to the discharge with the pump warm (1.4 mTorr compared to $4.0 \mathrm{mTorr})$ and the resulting lower fueling source for the core plasma may account for the remainder of the reduction in density rate of rise. A pumping rate of $13 \mathrm{Torr} / / \mathrm{s}$ corresponds to a density change time $\mathrm{N} /(\mathrm{dN} / \mathrm{dt})$ of about one second, which is low enough compared to $\tau_{E} \sim 0.3 \mathrm{~s}$ to be an effective particle removal rate in ELM-free $\mathrm{H}$-mode.

This favorable result is consistent with earlier detailed work on particle confinement (Rensink et al., 1993). In that work, the DEGAS Monte-Carlo neutral particle transport code, calibrated to neutral measurements, was used to calculate the neutral fueling source in the plasma core and hence, $\tau_{p}$. It was found that the ratio of $\tau_{p}$ to $\tau_{E}$ remained almost unchanged as the plasma went from $\mathrm{L}-$ to $\mathrm{H}$-mode. The six fold increase in $\mathrm{dN} / \mathrm{dt}$ after the $\mathrm{L}-\mathrm{H}$ transition was made up of a factor of 2 increase in $\tau_{p}$ and a factor of 3 increase in core fueling owing to reduced SOL opacity. Hence changes in the SOL dominate the large $\mathrm{dN} / \mathrm{dt}$ seen in $\mathrm{H}$-mode rather than the particles being unable to escape the core plasma. Our favorable pumping rate also indicates the particles can escape the core of ELM-free $\mathrm{H}$-mode at reasonable rates.

The results in ELM-free VH-mode were not so clear. The short ELM-free period made it difficult to see the development of the effect of pumping. The pumping rate dropped from $28 \mathrm{Torr} \ell / \mathrm{s}$ in L-mode to $7.5 \mathrm{Torr} \ell / \mathrm{s}$ in the VH phase. This rate is lower than the NBI fueling rate of $10 \mathrm{Torr} \ell / \mathrm{s}$. The density rate of rise in the unpumped discharge was $34 \mathrm{Torr} \ell / \mathrm{s}$ and was either unchanged or perhaps as low as 25 Torr $/$ /s with pumping. The neutral pressure near the midplane was low in all these discharges (see Table 1). In fact the pressure of $1.5 \mathrm{~m}$ Torr in the unpunped VH case was as low as the pressure of $1.4 \mathrm{mTorr}$ in the pumped $\mathrm{H}$-mode case. The density rates of rise in the VH cases, pumped or unpumped, were about the same as the 
pumped H-mode case. It may be that the great efforts (HeGWC) made to maximize the wall pumping to obtain VH-mode result in the pump being less effective with respect to the wall pumping. It should also be kept in mind that these VHmode plasmas were poor performers in regard to $\mathrm{H}$ factor and robustness of the SOL.

\section{Impurity control}

The installation of the allgraphite wall in DII-D in January, 1993 completely eliminated the accumulation of high $Z \mathrm{im}$ purities previously seen in high current $\mathrm{VH}$-mode plasmas (Konoshima et al., 1992; Konoshima et al., 1993). The high $Z$ accumulation has not been replaced by an accumulation of low $Z$ impurities (Wood et al., 1993). Carbon is the main impurity ion giving $1 \leq Z_{\text {eff }} \leq$ 2 and carbon does not accumulate in ELM-free phases.

Previous extensive studies of impurity transport in $\mathrm{H}$-mode (Content et al., 1990; Perry et al., 1991) showed that impurity density profiles generally take the same shape as the electron density profiles with just a bit of the accentuation implied by neoclassical transport theory $\left[n_{z}(r) \sim\right.$ $\left.n_{e}^{z}(r)\right]$. Since H-mode density profiles are flat or even
7974579744

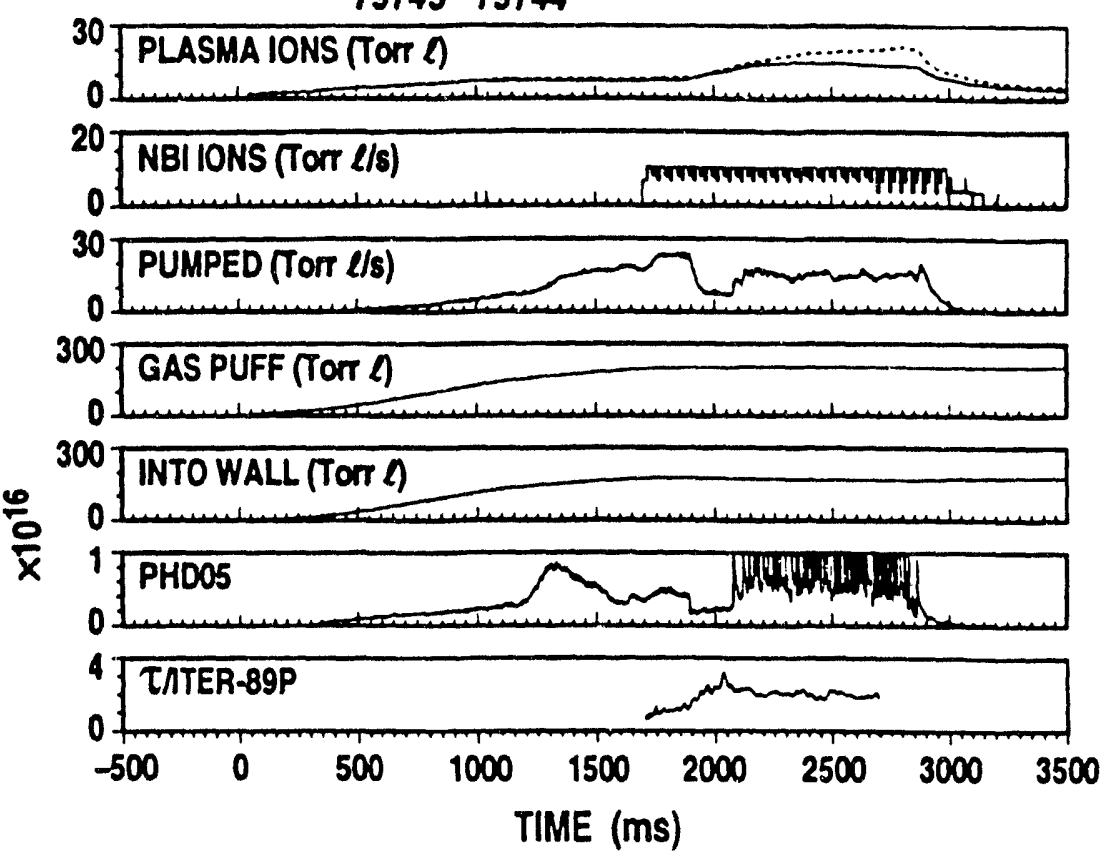

7988479882
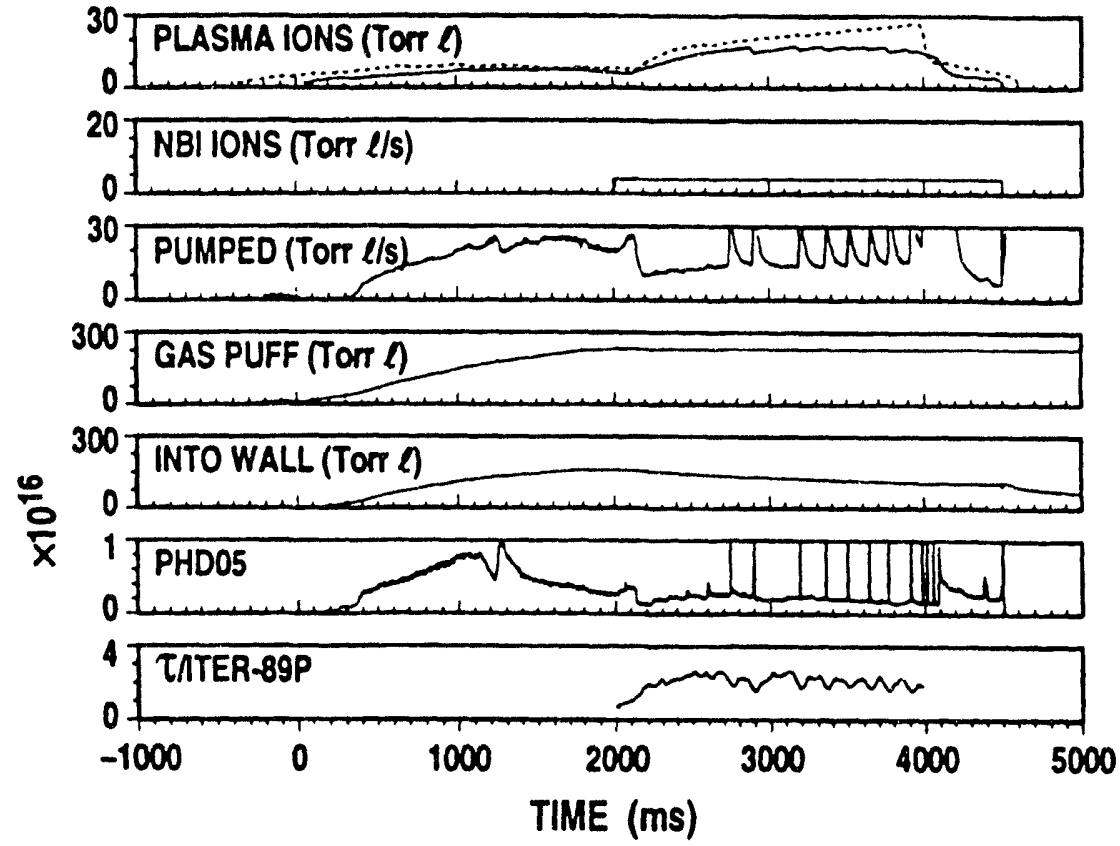

Figure 5. Time traces for a pumped H-mode (79884) and pumped VH-mode (79745) discharge. Traces in order are (1) plasma ion content in Torr $\ell$ (the dashed trace is an unpumped reference discharge with the trace shifted to line up the L-H transitions.), (2) neutral beam particle fueling rate, (3) cryopumping rate in Torr $\ell / s,(4)$ integrated gas puff input, (5) integrated particles absorbed by the wall, (6) $D_{\alpha}$ photodiode light (recycling monitor), (7) confinement enhancement over ITER-89P scaling. 
hollow, substantial quantities of the impurities reside within one ELM depth $(0.3 \mathrm{~A})$ from the edge and are thrown out of the plasma with each ELM. Since most impurities of concern stick to the walls, this is an effective impurity control mechanism.

It may be advantageous to deliberately re-introduce noble gas impurities into the core of $\mathrm{H}-$ and VH-mode plasmas to assist in solving the divertor problem. Since ITER only requires confinement performance of $\mathrm{H} \sim 1.6$, VH-mode plasmas with $\mathrm{H} \sim 4$ have a large excess of confinement quality; additional intentional radiative losses in a cooled mantle just inside the separatrix could be tolerated. In DIII-D, neon has been puffed into $\mathrm{H}$-mode discharges in sufficient quantities to lower the peak heat flux to the divertor plates by a factor of 5 , increase core $Z_{\text {eff }}$ to 3 , and produce a radiating mantle about $7-8 \mathrm{~cm}$ thick $\left(\mathrm{P}_{\mathrm{r}} / \mathrm{P}_{\text {input }}=60 \%\right)$ while maintaining $H \sim 1.8$ (Petrie etal., 1993). Besides lowering the peak heat flux to the divertor plate, the radiation can lower the electron temperature on the separatrix enough that the electron-ion equilibration length in the SOL is less than the length of the field lines. This e-i coupling may be the only way to lower $T_{i}$ below the sputtering threshold before the ions hit the divertor plate.

\section{Conclusion}

Besides the improved confinement afforded by $\mathrm{H}$ - and $\mathrm{VH}$-mode, these modes have other favorable properties for reactor application. Careful particle transport studies showed that the ratio of $\tau_{\mathrm{p}}$ to $\tau_{\mathrm{E}}$ was unchanged between $\mathrm{L}$ - and $\mathrm{H}$-mode (Rensink et al., 1993). With the cryopump in DIII-D, pumping rates of deuterium adequate for a reactor have been seen in ELMing and ELM-free H-mode. (Mahdavi et al., 1993b) Results in VH-mode are less clear owing to the poor quality $\mathrm{VH}$-mode plasmas that are compatible with the present position of the cryopump in DIII-D. Adequate pumpout of helium $\left(\tau_{\mathrm{HE}}^{*} / \tau_{\mathrm{E}} \sim 14\right)$ has been obtained in ELMing H-mode (Hillis et al., 1993). Removal of the source of high $Z$ impurities did not result in accumulation of low $Z$ impurities in VH-mode(Wood et al., 1993). The flat density profiles and ELMs provide an effective impurity control mechanism (Content et al., 1990; Perry et al., 1991). In DIII-D quantities of neon large enough to significantly lower the peak heat flux to the divertor plate were compatible with reasonable confinement $(\mathrm{H} \sim 1.8)$ (Petrie et al., 1993). The excess of confinement afforded by $\mathrm{VH}$-mode may allow core impurity radiation to assist in solving the divertor problem.

\section{References}

Mahdavi, M.A., etal., (1993a). Proc. 20th Euro. Conf. on Controlled Fusion and Plasma Physics, Lisboa, Vol. 17C, p. 647.

Mahdavi, M.A., et al., (1993b). Proc. 15th IEEE/NPSS Symp. on Fusion Engineering, Massachusetts, to be published in J. of Fusion Technol..

Hillis, D.L., etal., (1993). this conference; Wade, M.R., etal., (1993). Bull. Am. Phys. Soc. 38, 1936.

Konoshima, S., etal., (1992). Bull. Am. Phys. Soc. 37, 1509.

Konoshima, S., et al., (1993). Bull. Am. Phys. Soc. 38, 2062.

Wood, R.D., et al., (1993). Bull. Am. Phys. Soc. 38, 2064.

Lippmann, S.I., et al., (1992). Proc. 10th Intnl Conf. on Plasma Surface Interactions, Monterey.

Content, D.A., et al., (1990). Nucl. Fusion 30, 701.

Perry, M., (1991). General Atomics Report GA-A19286.

Schissel, D.P., et al., (1993). Bull. Am. Phys. Soc. 38, 1938.

Lazarus, E.A., etal., (1993). Bull. Am. Phys. Soc. 38, 1936.

Stambaugh, R.D., et al., (1990). Phys. Fluids B2, (12), 2941.

Rensink, M.E., et al., (1993). Phys. Fluids B.

Petrie, T.W., et al., (1993). Bull. Am. Phys. Soc. 38, 2071. 

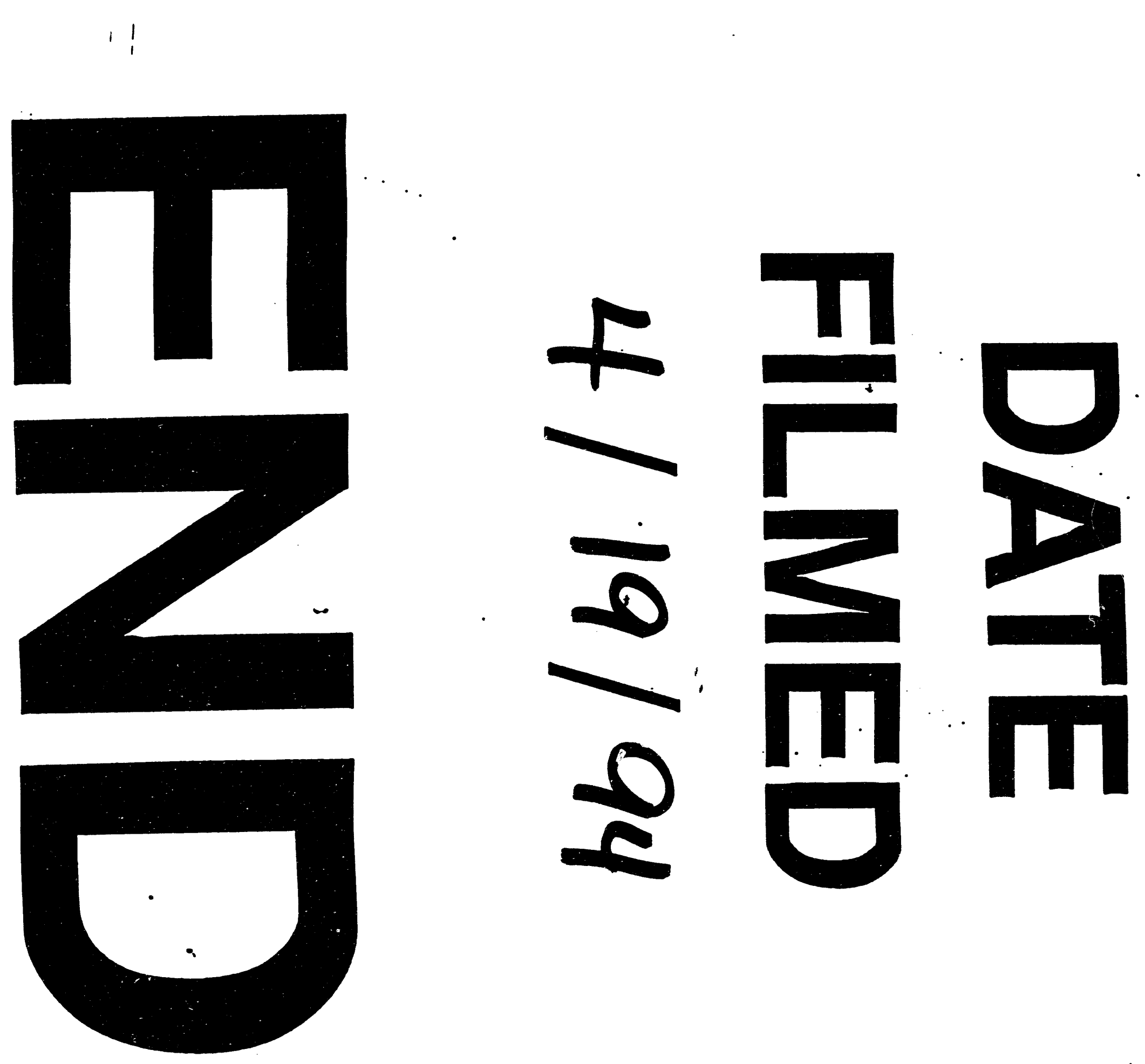
